\title{
ANÁLISE DA PARCELA COMO UNIDADE TERRITORIAL DO CADASTRO URBANO BRASILEIRO
}

\author{
Analysis of the parcel as a land unity of the Brazilian urban cadastre \\ JUCIELA CRISTINA DOS SANTOS \\ EDLA SIQUEIRA DE FARIAS \\ ANDREA FLÁVIA TENÓRIO CARNEIRO \\ Universidade Federal de Pernambuco - UFPE \\ Centro de Tecnologia e Geociências \\ Departamento de Engenharia Cartográfica \\ Av. Acad, Hélio Ramos, s/n \\ 50740-530 - Recife - Pernambuco - Brasil \\ juciela_agrimensura@yahoo.com.br; edla.farias@gmail.com; \\ aftc@ufpe.br
}

\begin{abstract}
RESUMO
Um dos princípios básicos do cadastro multifinalitário é a padronização da sua unidade territorial, uma vez que o compartilhamento de informações exige a adoção de uma unidade cadastral única. Situações de ordem prática, observadas em áreas rurais e urbanas, geram dúvidas quanto à aplicabilidade, no Brasil, do conceito de parcela como a menor unidade do cadastro e como uma porção do território com condições homogêneas de domínio. A partir destas observações, este artigo teve como objetivo avaliar a adoção do conceito de parcela, com base em sistemas internacionais e em casos práticos do cadastro brasileiro, utilizando como estudo de caso o cadastro de Arapiraca-AL. Os resultados indicaram que a consideração da parcela como uma porção do solo possuída por uma pessoa ou por várias pro indiviso é adequada e compatível com o conceito de condição homogênea de domínio. A pesquisa confirma ainda a viabilidade da adoção da parcela como menor unidade do cadastro, não admitindo, assim, a existência de subparcelas, mas objetos territoriais associados a estas parcelas, como orienta o documento Cadastro 2014.

Palavras-chave: Parcela; Unidade Cadastral; Cadastro Territorial Multifinalitário.
\end{abstract}


One of the basic principles of multipurpose cadastre is the standardization of its territorial unity, since information sharing requires the adoption of a single cadastral unit. Practical situations, observed in urban and rural areas, raise doubts concerning the applicability in Brazil, of the concept of parcel as the smallest unit of the Cadastre and as a portion of the territory with domain with homogeneous conditions. From these observations, this study aimed at evaluating the adoption of the parcel concept, based on international systems and cases of Brazilian cadastre, using as a case study the cadastre of Arapiraca-AL. The results indicated that the consideration of the parcel as a soil portion owned by a person or several "pro indiviso" is suitable for and compatible with the concept of a domain homogeneous condition. The research also confirmed the feasibility of adopting the parcel as the smallest unit of the Cadastre, not admitting sub-parcels, but territorial objects associated with these parcels, according to 2014 Cadastre.

Keywords: Parcel; Cadastral Unity; Multipurpose Cadastre.

\section{INTRODUÇÃO}

No Brasil, a disponibilidade das mais modernas técnicas de levantamento, processamento, tratamento e análise de dados espaciais não se traduz na implantação de sistemas de informações territoriais eficientes no âmbito cadastral. Como conseqüência, as atividades de gestão territorial não têm sido capazes de evitar graves danos para o país, como se observa nos casos de prejuízos causados por desastres naturais nos últimos anos, por exemplo.

Analisando-se a atual estrutura do cadastro brasileiro, pode-se concluir que a razão para esse descompasso entre o domínio tecnológico e a eficiência da sua aplicação no âmbito cadastral está no campo conceitual. A aplicação de tecnologias sofisticadas deve ser apoiada em conceitos sólidos e perenes, para garantir o retorno do investimento em termos de benefícios para a sociedade.

A aproximação com os princípios e conceitos internacionais de cadastro deuse somente a partir da Lei 10.267/01, com a exigência do intercâmbio entre cadastro e registro e do georreferenciamento de imóveis rurais. Desde então, surgiram outras iniciativas voltadas para o aperfeiçoamento do cadastro urbano, como a publicação da Portaria n.511/09, do Ministério das Cidades, que propõe diretrizes para a implementação de Cadastro Territorial Multifinalitário (CTM) nos municípios brasileiros.

Um dos conceitos que representa o princípio básico do cadastro multifinalitário é o conceito de parcela. Sem a padronização de uma unidade cadastral com identificador único, não é possível o compartilhamento de informações. A proposta das diretrizes acima referidas aproxima-se deste conceito, quando sugere que o CTM seja modelado com base em um sistema de referência único e um identificador único e estável para cada parcela. 
A partir da compreensão da necessidade da adoção de um conceito único para a unidade cadastral, o próximo desafio é a sua modelagem. Situações de ordem prática, observadas tanto em áreas rurais quanto em áreas urbanas, geram dúvidas quanto à aplicabilidade do conceito de parcela como "uma porção do território com condições homogêneas de domínio”, bem como “ a menor unidade do cadastro”.

Partindo destas observações, este artigo tem como objetivo analisar diferentes concepções para o conceito de parcela, analisando propostas internacionais e alguns casos reais encontrados comumente em áreas urbanas brasileiras. O estudo baseou-se na busca de resposta às seguintes questões:

1- A parcela, menor unidade do cadastro, refere-se ao solo ou à edificação?

2- Se a parcela é uma porção do solo com condições homogêneas de domínio, como tratar os casos dos domínios individualizados por construções (como o caso dos apartamentos e condomínios)?

3- Como esses casos são tratados nos países que adotam esses conceitos?

\section{A PARCELA COMO ELEMENTO FUNDAMENTAL DO CADASTRO}

O conceito de cadastro que representa um consenso internacional é bem conhecido: Cadastro é um inventário público de dados metodicamente organizados, concernentes a parcelas territoriais, dentro de uma determinada região administrativa, baseado no levantamento dos seus limites. É adotado por diversos autores (WILLIAMSON, 1983; DALE E MCLAUGHLIN, 1990) e recomendado pela FIG (Federação Internacional de Geômetras). Também é o conceito sugerido pela Portaria 511, do Ministério das Cidades (BRASIL, 2009).

A parcela é considerada a unidade básica do cadastro, e sua definição mais difundida estabelece essa unidade como sendo correspondente a uma uma porção do território com condições homogêneas de domínio. Para Jing (2011), essa definição é flexível e adapta-se aos diversos sistemas cadastrais, já que cada país possui um sistema que reflete as características político-administrativas de sua legislação.

Alcázar-Molina (2010) explica que antes de qualquer ação para a implementação de um cadastro, é necessário determinar claramente o que se considera inmueble catastral (a parcela na Espanha), sem prejuízo de outras descrições que possam existir. No Brasil, por exemplo, coexistem conceitos diferentes de imóvel rural, de acordo com o objetivo (fundiário ou tributário). O autor recomenda, para se estabelecer a unidade a ser cadastrada, que se realize uma profunda análise:

- do objetivo da individualização, física e jurídica, dos bens;

- dos conceitos de bens imóveis existentes (no Código Civil e em outras legislações: agrárias, de uso do solo);

- do conceito de bem imóvel adotado pelo registro imobiliário.

Estas informações devem orientar a busca de uma referência cadastral única que identifique perfeitamente o bem. 


\subsection{Diferentes Interpretações de um Mesmo Conceito}

As relações estabelecidas entre governos e entidades buscando o aprimoramento do cadastro sempre tiveram que buscar um entendimento comum sobre conceitos e termos relacionados aos temas cadastrais. Neste sentido, destacam-se as iniciativas da FIG - Federação Internacional de Geômetras, com o documento Cadastro 2014 (KAUFMANN E STEUDLER,1998); a elaboração da Diretiva INSPIRE - Infraestrutura Nacional de Dados Espaciais (INSPIRE,2010), da União Européia; e a publicação mais recente, a ISO 19152 (ISO,2012), referente ao Modelo de Domínio para Administração Territorial (Land Administration Domain Model- LADM). Paixão et.al (2012) apresentam um estudo teórico sobre a estruturação de um cadastro multifinalitário, baseado em alguns destes documentos.

Martín-Varés (2009) participou do grupo de trabalho responsável pelas especificações técnicas de cadastro para a diretiva INSPIRE, a Infraestrutura de Dados Espaciais européia. De acordo com a autora, o problema do conceito cadastral, discutido em reuniões com instituições de vários países, foi encontrado não apenas na diversidade de idiomas e suas traduções. Mesmo falando a mesma língua, como na maior parte da América Latina, os sistemas cadastrais são tão heterogêneos, e existem tantas diferenças na terminologia, que muitas vezes torna-se de difícil entendimento. O grupo teve como objetivo estabelecer exigências mínimas para que o cadastro seja integrado à INSPIRE, mantendo as características cadastrais e legais dos sistemas nacionais. Como resultado, a parcela é definida genericamente como o elemento mínimo para o dado espacial, ou a área definida por registro cadastral ou equivalente (INSPIRE,2010).

Já o conhecido modelo Cadastro 2014 (KAUFMANN E STEUDLER,1998) introduz um novo conceito, de objeto territorial, e o diferencia do conceito de parcela:

- Parcela: porção de terra com limites definidos, sobre a qual se aplica o direito de propriedade a um indivíduo ou pessoa jurídica.

- Objeto territorial: porção de terra com condições homogêneas em seus limites. Um Objeto territorial legal é descrito pelo conteúdo legal de um direito ou restrição e pelos limites nos quais estes direitos e restrições se aplicam. Como exemplos de objetos territoriais legais, pode-se citar as parcelas de propriedade privada, áreas onde existam direitos tradicionais, unidades administrativas, zonas de proteção (água, ruído, poluição), zoneamento de uso. Quando este objeto territorial possui condições homogêneas sem um caráter legal, este pode ser denominado objeto territorial físico, a exemplo de construções ou ruas.

A partir do estudo destas experiências e proposições, percebeu-se a necessidade de ampliar a análise para além das tentativas de padronização, e estudar a aplicação destes conceitos em alguns países da Europa e América Latina.

Para Martín-Varés (2009), em países como Alemanha, França e Bélgica, a parcela é o objeto sobre o qual é exercido o direito formal (relação entre o indivíduo e a terra) e deve ser identificada inequivocamente por um número e por limites 
topográficos. Por outro lado, segundo a autora, os países nórdicos reconhecem uma unidade básica de propriedade, que pode ter várias parcelas identificadas no terreno. De acordo com UN-CE (2004), a Unidade de Propriedade Básica - UPB (sigla em inglês BPU), é definida como uma porção de terra com situação homogênea de posse ou direitos reais de propriedade, podendo ser constituída de várias parcelas.

Na América Latina também são observados conceitos distintos de parcela. Estudos estão sendo desenvolvidos por comitês e órgãos cadastrais para estabelecer um panorama sobre o cadastro latino e alguns países estão trabalhando na estruturação de um sistema cadastral nacional, ou investindo em seu aprimoramento. Os resultados da pesquisa realizada pelo Comitê Permanente de Cadastro na Iberoamérica - CPC foram publicados na revista DataCatastro (CPCI,2009; CPCI,2011). Segundo Martíns-Varés (2009), a Venezuela reconhece a parcela como a unidade cadastral por excelência, definida como a porção do terreno, com construção ou não, delimitada por uma poligonal fechada, localizada dentro de um município, possuída por um proprietário ou por vários pro indiviso.

Já na Argentina, a parcela é definida, na Lei Nacional $n^{\circ} 26.209$ (REPUBLICA ARGENTINA, 2007), como a representação da coisa imóvel de extensão territorial contínua, delimitada por um polígono de limites correspondente a um ou mais títulos jurídicos ou a uma posse exercida, cuja existência e elementos essenciais constem em um documento cartográfico e registro no organismo cadastral.

Em resumo, foram identificadas as seguintes situações:

a) a parcela é o solo, a unidade mínima do cadastro, possuída por uma pessoa;

b) a parcela é o solo, a unidade mínima do cadastro, possuída por uma pessoa ou por várias pro indiviso (exemplo de condomínios e apartamentos);

c) a unidade básica pode ser constituída de várias parcelas (exemplo da UPB); a parcela é o solo e pode ser constituída de objetos territoriais individualizados (como construções, reserva legal, áreas de restrição).

Esse estudo norteou a análise da adoção da parcela como unidade do cadastro brasileiro, apresentada a seguir.

\subsection{Adoção da Parcela como Unidade Territorial do Cadastro no Brasil}

Brandão (2003) apresenta uma proposta para a adoção da parcela como unidade cadastral no Brasil, com as seguintes características:

a) Continuidade espacial, ou seja, todo o território é considerado, dividido em parcelas, sendo que cada uma delas faz limite sempre com outra;

b) Unicidade dominial, ou seja, cada parcela só pode ser apropriada ou possuída por uma pessoa, física ou jurídica;

c) Mesma situação jurídica, ou seja, cada parcela apresenta uma única condição legal, por exemplo, propriedade particular, propriedade pública, posse; 
d) Mesma situação administrativa, ou seja, a parcela deve respeitar as divisões administrativas do território, devendo fazer parte, por exemplo, de um único estado, município, distrito, bairro, zona urbana, zona rural, etc;

e) Mesmo uso, ou seja, cada parcela deve ter um uso exclusivo, por exemplo, cultivo, construção, circulação, reserva ambiental, etc.

Analisando esta proposta a partir do estudo apresentado no item 2.1, pode-se sugerir que, de acordo com os conceitos do Cadastro 2014, os casos de mesmo uso e situação administrativa sejam considerados como objetos territoriais, já que uma parcela com situação jurídica homogênea pode apresentar dois tipos de uso em seus limites, por exemplo.

Em 2009, o Ministério das Cidades publicou a Portaria ministerial $n^{0} 511$ (BRASIL,2009) referente às diretrizes para a criação, instituição e atualização do Cadastro Territorial Multifinalitário (CTM) nos municípios brasileiros, definido como o inventário territorial oficial e sistemático do município e embasado no levantamento dos limites de cada parcela, que recebe uma identificação numérica inequívoca. De acordo com o artigo segundo desta portaria, a parcela cadastral é a menor unidade do cadastro, definida como uma parte contígua da superfície terrestre com regime jurídico único. Ainda segundo a Portaria:

“§ $1^{\circ}$ É considerada parcela cadastral toda e qualquer porção da superfície no município a ser cadastrada;

$\S 2^{\circ}$ As demais unidades, como, lotes, glebas, vias públicas, praças, lagos, rios e outras, são modeladas por uma ou mais parcelas de que trata o caput deste artigo, identificadas por seus respectivos códigos;

$\S 3^{\circ}$ Deverá ser atribuído a toda parcela um código único e estável.”

O documento especifica, ainda, em seus décimo e décimo terceiro artigos, que o levantamento cadastral para a identificação geométrica das parcelas territoriais deve ser referenciado ao Sistema Geodésico Brasileiro - SGB e os vértices que definem os limites de cada parcela devem constituir uma figura geométrica fechada.

A fim de testar a viabilidade de aplicação destes conceitos e responder às perguntas colocadas na introdução deste trabalho, foi realizada a análise de situações reais, utilizando dados do cadastro do município de Arapiraca-Al.

\section{ANÁLISE DA ADOÇÃO DA PARCELA EM ALGUMAS SITUAÇÕES COMUNS NO CADASTRO URBANO BRASILEIRO}

Considerando a complexidade de situações vivenciadas na rotina de uma organização cadastral, e visando contribuir com os municípios na modelagem da parcela como unidade cadastral, conforme orienta a Portaria 511, foi realizada a análise de algumas situações reais, que suscitam dúvidas na aplicação desses conceitos.

Os dados utilizados no experimento pertencem à base do cadastro do município de Arapiraca-AL, portanto a forma de armazenamento e o seu conteúdo podem diferir dos cadastros de outros municípios brasileiros. Considera-se, no 
entanto, que os casos apresentados servem para uma reflexão sobre as situações tratadas à luz do estudo teórico apresentado, e podem contribuir para a indicação de soluções a serem adotadas por municípios em condições similares às de Arapiraca.

Antes das análises dos casos particulares, é importante destacar algumas questões importantes, especialmente quando se pretende considerar a parcela como unidade com condições homogêneas de domínio:

a) A unidade territorial do registro de imóveis é o bem imóvel, que deve ser caracterizado inequivocamente e indicar o registro que lhe deu origem. $\mathrm{O}$ registro contém apenas os imóveis formais, legalizados.

b) A unidade territorial comumente adotada no cadastro dos municípios brasileiros é o imóvel. Na maioria dos casos, apenas os imóveis tributáveis. O cadastro pode conter imóveis formais e informais. Além disso, um imóvel pode ser constituído por mais de uma situação de domínio.

\subsection{Individualização da Unidade Cadastral em Arapiraca-AL}

A criação de um identificador único para cada parcela cadastral está inicialmente relacionada apenas com o terreno, porém as edificações que compõem a parcela cadastral podem também possuir identificadores no cadastro, sendo estas caracterizadas como unidades autônomas ou unidades de avaliação.

Essa situação ocorre por diversos motivos, sendo o mais freqüente o interesse dos possuidores de realizar o pagamento do Imposto Predial Territorial Urbano (IPTU) somente da parcela que ocupa, sendo esta individualizada.

No cadastro imobiliário podem ser abertas subunidades cadastrais para o mesmo imóvel, segundo três características:

a) Localização: quando a parcela possui parte urbana e parte rural;

b) Regime Jurídico: quando as construções no mesmo lote pertencem a mais de um possuidor e o acesso às edificações são independentes, sendo o proprietário de direito e/ou proprietário de fato;

c)Uso distinto: quando a construção ou o terreno possui mais de um uso, residencial/comercial, no caso das construções, ou uso rural/urbano no caso do terreno.

No caso das construções, cada unidade recebe um identificador único, ligado a uma inscrição cadastral principal que se refere, geralmente, ao terreno. As unidades de avaliação são ligadas, obrigatoriamente, a alguma unidade autônoma já existente.

\subsubsection{Caso 1}

A Figura 1 apresenta uma situação comum nos municípios brasileiros. O exemplo mostra três edificações em um único lote. Como pode ser observado, o uso do imóvel é misto, onde as edificações possuem uso comercial e residencial. Além disso, cada uma possui um detentor com contrato de usufruto, ou seja, apresentam possuidores distintos.

A situação cadastral desses imóveis no município é a seguinte: 
Imóvel 01 - de uso comercial, pertencente ao proprietário registrado, ou seja, a edificação pertence ao dono do lote.

Imóvel 02 - de uso comercial, o possuidor tem contrato de usufruto.

Imóvel 03 - de uso residencial, o possuidor tem contrato de usufruto, edificação localizada no primeiro pavimento, com sobreposição nas duas edificações térreas.

Figura 1 - Caso 1: mesma matrícula, diferentes possuidores e usos das edificações.

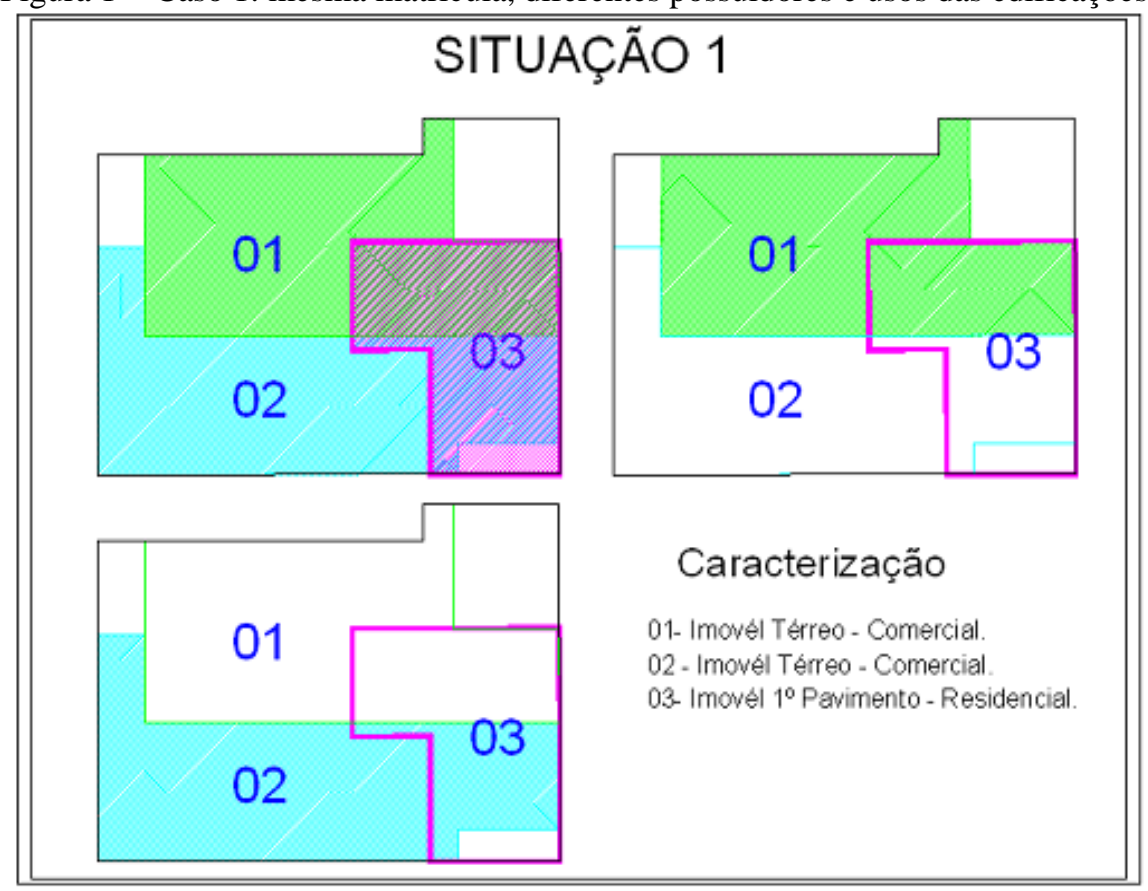

Dessa forma, a situação cadastral das parcelas do imóvel ilustrado na Figura 1 fica definida pela abertura de um geocódigo para cada edificação, com separação das áreas e individualização dos possuidores de cada unidade, porém conservando o proprietário (aquele que consta no registro) em todas as unidades cadastrais abertas pela prefeitura (Figura 2). Assim, é possível a identificação de cada unidade, sendo cada uma das parcelas tratada de forma separada.

Analisando o caso sob o ponto de vista dos conceitos de parcela e objetos territoriais apresentados no item 2.1, observa-se que o solo possui condição homogênea de domínio (uma matrícula, uma parcela), porém as edificações apresentam possuidores distintos (objetos territoriais físicos distintos, delimitados 
dentro da parcela). O uso também é individualizado pelas construções (residencial e comercial, objetos territoriais distintos).

A análise indica que o cadastro de Arapiraca tem como unidade cadastral a parcela, uma porção de solo. A cada parcela podem ser associados objetos territoriais, para individualização de situações distintas sobre a mesma porção de terreno.

Figura 2 - Representação do Caso 1 no cadastro de Arapiraca-AL.

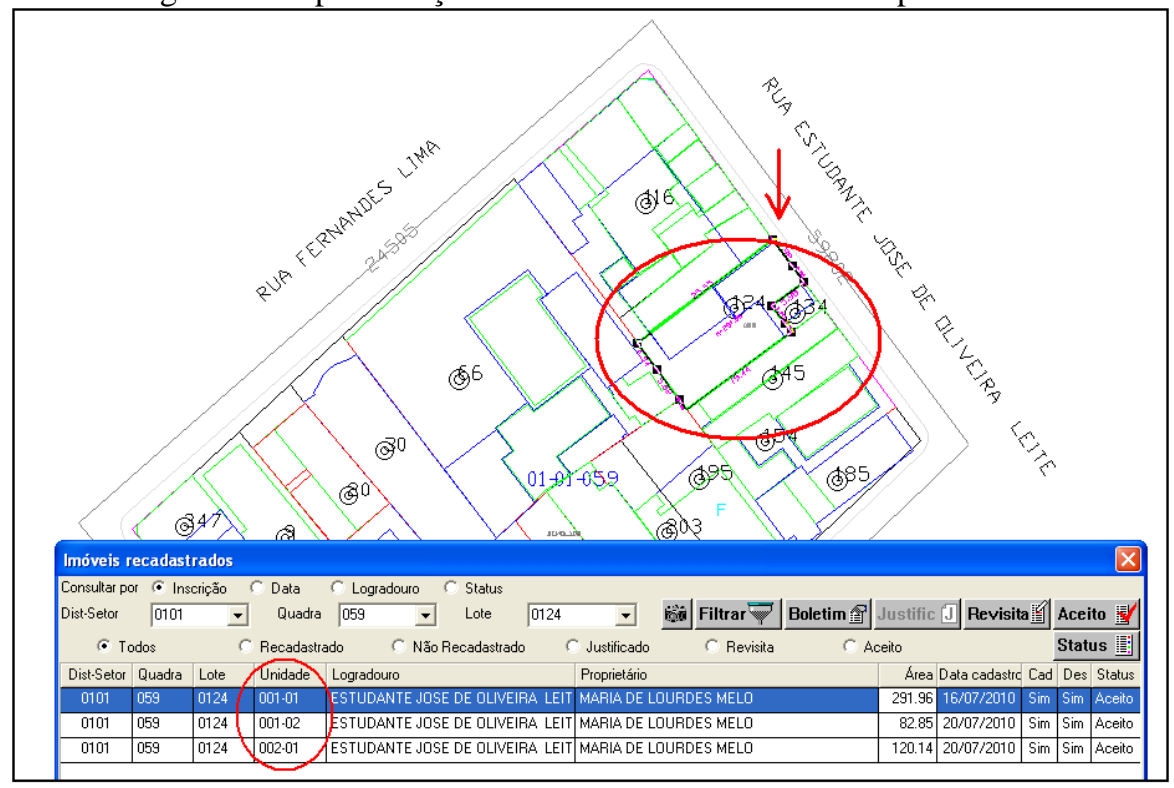

É importante destacar o papel do cadastro da parcela na identificação da situação da posse (situação de fato, física) do bem imóvel, que pode contribuir para uma futura legalização, quando possível.

Analisando-se o caso apresentado à luz de uma possível legalização, pode-se dizer que este retrata uma situação de posse conjunta de mesma unidade de terreno. O artigo primeiro da lei 4.591(BRASIL,1964), que trata de condomínios, dispõe: "As edificações ou conjuntos de edificações, de um ou mais pavimentos, construídos sob a forma de unidades isoladas entre si, destinadas a fins residenciais ou não-residenciais, poderão ser alienados, no todo ou em parte, objetivamente considerados, e constituirá cada unidade, propriedade autônoma sujeita às limitações desta Lei”.

As construções deste exemplo, situadas num mesmo lote, com um único proprietário, podem tornar-se legalmente independentes, na forma de condomínio, refletindo no registro de imóveis uma situação identificada no cadastro territorial. 


\subsubsection{Caso 2}

A Figura 3 ilustra o caso de um imóvel que possui uma matrícula (situação jurídica) e quatro situações distintas de posse. As parcelas 01 e 03 surgiram a partir de uma desapropriação para o prolongamento de uma rua existente. Com isso, o imóvel registrado teve a sua continuidade interrompida pela parcela de número 02, referente ao trecho de logradouro criado após a desapropriação (de domínio público). A parcela 04, onde se localiza a residência do proprietário, foi incorporada ao imóvel. Esta, por sua vez, foi adquirida informalmente, sem transferência de propriedade no registro, caracterizando-se como posse, e não propriedade.

Assim, são identificadas no mesmo imóvel quatro parcelas e três regimes jurídicos: propriedade privada nas parcelas 01 e 03; propriedade pública na parcela 02 e posse na parcela 04 . No cadastro municipal, as parcelas territoriais são apresentadas na forma representada na Figura 3, com identificadores únicos e um dígito diferencial para individualizar cada parcela. As edificações existentes em todas as parcelas também podem ser representadas como unidades autônomas ou de avaliação, sendo criadas subunidades cadastrais (objetos territoriais), dependendo da situação.

Figura 3: Imóvel constituído de parcelas no cadastro de Arapiraca-AL.

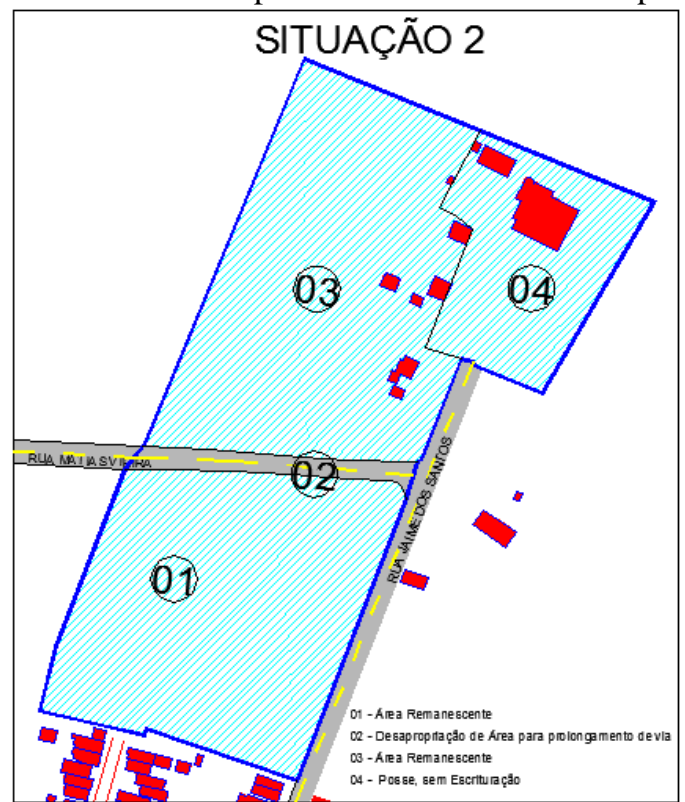

Bol. Ciênc. Geod., sec. Artigos, Curitiba, v. 19, no 4, p.574-587, out-dez, 2013. 


\section{RESULTADOS E DISCUSSÃO}

Analisando os dois casos, considerando os conceitos estudados, pode-se responder às questões que motivaram o desenvolvimento deste trabalho.

Se a parcela é a menor unidade do cadastro, admite-se subparcelas? O caso 1 representa uma situação na qual solo e construções não apresentam situações homogêneas de domínio. Se o conceito de parcela considera o solo como unidade cadastral, então pode-se concluir que a parcela é a menor unidade do cadastro, e pode ser constituída por objetos territoriais físicos e legais, como propõe o documento Cadastro 2014. Estes objetos estão relacionados à unidade parcela e não se constituem em subparcelas.

A mesma consideração é válida para a individualização do uso, onde o caso 1 indica uma possibilidade em que existe uma situação jurídica homogênea (uma matrícula) com usos distintos, que também pode ser equacionada com a individualização de objetos territoriais que indicam os limites destes usos. Situação semelhante à apresentada no caso 1 é a dos apartamentos, onde sobre uma mesma porção de solo existem situações distintas de propriedade. Essa aparente contradição pode levar à conclusão de que a parcela deve ser a construção e não o solo, no entanto a proposta do Cadastro 2014 resolve a questão ao considerar a parcela constituída por objetos territoriais. Esta situação está também de acordo com a proposta da Portaria 511.

Uma análise que corrobora este resultado é apresentado por Alcázar-Molina (2010) e permite a concordância com o conceito inicial, da parcela como sendo uma porção do solo. $\mathrm{O}$ autor apresenta a definição de bem imóvel da lei espanhola de cadastro, que estabelece: para os exclusivos efeitos cadastrais, considera-se bem imóvel a parcela ou porção do solo de uma mesma natureza, situada nos limites municipais, e cercada por um polígono fechado que delimita, a tais efeitos, o âmbito espacial do direito de propriedade de um proprietário ou de vários pro indiviso. Neste caso, a parcela inclui as construções localizadas neste âmbito, qualquer que seja seu dono, e com independência de outros direitos que recaiam sobre o imóvel. Essa definição, segundo o autor, tenta reunir todas as inquietudes existentes e ajustar-se à realidade.

A análise de Alcázar-Molina (2010) aplica-se aos casos apresentados e concorda com a legislação brasileira, já que no caso de condomínios e apartamentos, por exemplo, o solo é possuído por todos, pro indiviso.

O caso 2 indica que o cadastro do município de Arapiraca segue as orientações das diretrizes, uma vez que individualiza cada situação jurídica do imóvel, individualizando cada parcela que integra o imóvel.

A utilização do conceito de objetos territoriais atende às situações analisadas, permitindo a individualização de limites que não possuem, como a parcela, o caráter de limite de propriedade.

Uma pesquisa realizada por Santos (2012) utilizou este estudo como base para a modelagem do CTM de Arapiraca de acordo com a ISO 19.152 (ISO,2012), confirmando a viabilidade de aplicação destes resultados. 


\section{CONCLUSÕES}

A adoção da parcela como unidade do cadastro é um dos fundamentos de um cadastro territorial multifinalitário, porém a sua modelagem exige estudos que demonstrem claramente as possibilidades de implementação para as diferentes situações de ordem prática.

Como foi apresentado neste artigo, o mesmo conceito é concretizado em cada país de uma maneira particular, de acordo com a sua realidade jurídica, técnica e administrativa. Para o caso brasileiro, a consideração da parcela como uma porção do solo possuída por uma pessoa ou por várias pro indiviso mostrou-se adequada nos casos analisados. A adoção do conceito de objetos territoriais resolve a questão da ligação do solo com a edificação, nos casos de posses distintas, e também de distintos usos e limites administrativos.

Embora esse trabalho tenha utilizado dados do município de Arapiraca para o teste da implementação dos conceitos, estes foram referenciados a leis federais brasileiras, de aplicação em todos os municípios. Por isso, embora os sistemas cadastrais possam diferir em conteúdo e forma de armazenamento, os princípios tratados aplicam-se a qualquer município que pretenda estruturar um cadastro territorial multifinalitário de acordo com a proposta da Portaria 511.

Finalmente, a pesquisa confirma a viabilidade da adoção da parcela como menor unidade do cadastro, não admitindo, assim, a existência de subparcelas, mas objetos territoriais associados a estes parcelas, como orienta o documento Cadastro 2014.

Recomenda-se a implementação e teste deste modelo para outras situações, inclusive para os casos de imóveis rurais, que apresentam características bastante diferenciadas de uso e posse. Este estudo também é fundamental para as situações nas quais o cadastro 2D não é suficiente para individualizar as diferentes situações de domínio do território acima e abaixo da superfície.

\section{AGRADECIMENTOS}

À Prefeitura Municipal de Arapirara, pela cessão dos dados analisados neste trabalho. Ao CNPq, pelo apoio financeiro através do Edital Universal - Processo n.477.565/2009-9. À CAPES, pela bolsa de mestrado da autora Edla Siqueira de Farias.

\section{REFERÊNCIAS BIBLIOGRÁFICAS}

ALCÁZAR-MOLINA, M. Catastro, Propiedad y Prosperidad. Jaén: Universidad de Jaén, 2010.

BRANDÃO, Artur Caldas. Princípio da Vizinhança Geodésica no Levantamento Cadastral de Parcelas Territoriais. 2003. 129 f. Tese (Doutorado em Engenharia de Produção) - Universidade Federal de Santa Catarina - UFSC, Florianópolis, 2003. 
BRASIL. Lei 4591, de 16 de dezembro de 1964. Diário Oficial da República Federativa do Brasil, Poder Executivo, Brasília, DF, 21 dez. 1964. Seção 1, p.11682.

BRASIL. Ministério das Cidades. Portaria n.511, de 7 de dezembro de 2009. Diário Oficial da República Federativa do Brasil, Poder Executivo, Brasília, DF, 08 dez. 2009. Seção 1, p.75.

COMITÉ PERMANENTE DEL CATASTRO EN IBEROAMÉRICA - CPCI. Caracterización de los Catastros en Iberoamérica. Revista DataCatastro CPCI. Ed.2. Espanha, novembro de 2009. 88p. Disponível em:http://www.catastrolatino.org/documentos/Datacatastro_edicion_2.pdf Acesso em:18.11.2011

COMITÉ PERMANENTE DEL CATASTRO EN IBEROAMÉRICA - CPCI. Resultados Data Catastro 2010 Según Ejes Temáticos Definidos. Revista Data Catastro - CPCI. Terceira Edição.Espanha, abril de 2011. 37 páginas. Disponível em: <http://www.catastrolatino.org/documentos/Datacatastro _edicion_3.pdf> Acesso em:18.11.2011

DALE, P. F.; MCLAUGHLIN, J. D. Land Information Management: An Introduction with Special Reference to Cadastral Problems in Third World. Oxford University Press, 1990.

FEDERAÇÃO INTERNACIONAL DE GEÔMETRAS - FIG. Statement on the Cadastre. Disponível em: <http://www.fig.net/commission7/reports/cadastre/ statement_on_cadastre.html>. Acesso em: 12 jul. 2010.

INFRASTRUCTURE FOR SPATIAL INFORMATION IN EUROPE - INSPIRE. D2.8.I.6 INSPIRE Data Specification on Cadastral Parcels - Guidelines. Thematic Working Group Cadastral Parcels, 2010. Disponível em: $<$ http://inspire.jrc.ec.europa.eu/documents/Data_Specifications/INSPIRE_Data Specification_CP_v3.0.pdf $>$. Acesso: 23.05.2011

ISO. Land Administration Domain Model (LADM) - ISO/FDIS 19152:2012. 2012.

JING, Y. Assessing Larsi-Integrated Participation Procedure for Urban Adjudication in China. Dissertação. University of Twente. Ensched, Holanda, 2011. 105 páginas. Disponível em: <www.itc.nl/library/papers_2011/msc/ la/jing.pdf> Acesso em: 28.mai.2011

KAUFMANN, J; STEUDLER, D. Cadastro 2014. Federação Internacional de Geômetras-FIG. 1998. Disponível em: http://www.fig.net/cadastre2014/ translation/c2014-english.pdf Acesso em 30.ago.2010.

MARTÍN-VARÉS, A. V. La importancia de llamarse Parcela Catastral. Revista catastro, $\mathrm{n}^{\circ}$ 66. Espanha, outubro de 2009. página 7 -23. Disponível em: http://www.catastro.meh.es/documentos/publicaciones/ct/ct66/1.pdf Acesso em: 22.11.11

PAIXÃO, Silvane K. S.; NICHOLS, Sue and CARNEIRO, Andrea F.T. Cadastro Territorial Multifinalitário: dados e problemas de implementação do convencional ao 3D e 4D. Boletim de Ciências Geodésicas, Curitiba, v.18, n.1, p.3-21, mar. 2012. ISSN 1982-2170.

Bol. Ciênc. Geod., sec. Artigos, Curitiba, v. 19, no 4, p.574-587, out-dez, 2013. 
REPUBLICA ARGENTINA. Ley Nacional de Catastro: Ley 26.209. Buenos Aires: Boletin Oficial de La Republica Argentina, 2007. 4 p. Disponível em: <http://gxportal.mendoza.gov.ar/archivos/catastro/Ley\%2026209.pdf>. Acesso em: 16 out. 2012.

SANTOS, J.C. Análise da aplicação do Modelo de Domínio de Conhecimento em Administração Territorial (LADM) ao Cadastro Territorial Urbano Brasileiro - Estudo de Caso para o Município de Arapiraca-AL . 2012. 131 f. Dissertação (Mestrado em Ciências Geodésicas e Tecnologias da Geoinformação) Universidade Federal de Pernambuco - UFPE, Recife, 2012.

UNITED NATIONS ECONOMIC COMMISSION FOR EUROPE- UN-ECE. Guidelines On Real Property Units And Identifiers. Nações Unidas. 2004. 80p. Disponível em: http://www.unece.org/fileadmin/DAM/env/documents/ 2005/wpla/Guidelines_On_Real_Property_Identifiers.pdf Acessado em: 22.11.11

WILLIAMSON, Ian. A modern Cadastre for New South Wales. Unisurv Report S23. Kensigton: The University of New South Wales, 1983. 257p.

(Recebido em maio de 2013. Aceito em setembro de 2013). 